\title{
CASOS DE HEMORRAGIA INTRACRANIANA EM SÃO PAULO-BRASIL: INCIDENCIA SOBRE ÓBITOS
}

\section{CASES OF INTRACRANIAL HEMORRHAGE IN SÃO PAULO-BRAZIL: FOCUSED ON DEATHS} \author{
Rafaela Silva Waltrick ${ }^{4}$. \\ 'UNINGÁ - Centro Universitário Ingá, Maringá, PR, Brasil. \\ ${ }^{2}$ Universidade do Contestado, Mafra, SC, Brasil. \\ ${ }^{3}$ Universidade Cesumar, Maringá, PR, Brasil. \\ ${ }^{4}$ Universidade do Vale do Itajaí, Itajai, SC, Brasil. \\ *manupalangani@gmail.com
}

Emanoelle Aparecida Palangani $\mathbf{1}^{*}$, Larissa Fernanda De Souza ${ }^{2}$, Jéssica Almeida Dall' Asta ${ }^{1}$, Sandro Artur Veit Bublitz ${ }^{3}$, Luana Hantequestt De Lima1,

\section{RESUMO}

A hemorragia intracraniana é caracterizada pelo inicial sangramento no parênquima encefálico, podendo acometer o espaço meníngeos e posteriormente os ventrículos. Os principais fatores de risco incluem, hipertensão arterial pré-adquirida; pertencer ao sexo masculino; idade avançada; uso de drogas ilícitas; dieta rica em gorduras, fatores genéticos relacionados ao estado do endotélio. Análise sobre óbitos por hemorragia intracraniana de São Paulo-Brasil, entre a faixa etária de 60 a 69 e 70 a 79, no espaço temporal de 2014 a 2019, assim como, a predominância em sexo e etnia. Foi feito no presente estudo coleta e análise de dados do DATASUS, recorrendo ao intervalo entre 2014 a 2019. Como critério de inclusão houve analise dos conteúdos de óbitos, comparando entre as faixas etárias de 60 a 69 anos e 70 a 79 anos, e a predominância em sexo e etnia; foi feito exclusão dentro de etnia a indígena, por falta de informações. A incidência de óbitos por hemorragia intracraniana, na faixa etária de 60 a 69 anos, no sexo masculino entre 2014 (212) e 2019 (270), um aumento de 27,36\%; analisando a questão da morte nas etnias, as pessoas brancas entre 2014 (114) e 2019 (143) aumentam 25,44\%; as pretas entre 2014 (9) e 2019 (22) aumentaram 144,44\%, enquanto as pardas entre 2014 (40) e 2019 (75) aumentaram 87,50\%; as amarelas entre 2014 (3) e 2019 (0) reduziram em 3 unidades. Na faixa etária de 70 a 79 anos, os óbitos, no sexo masculino entre 2014 (153) e 2019 (179) aumentaram 16,99\%. Analisando as respectivas etnias, a etnia branca em 2014 (92) e 2019 (106) aumentou 15,22\%, a preta, em 2014 (4) e 2019 (11) aumentou 175,00\%, a parda entre 2014 (24) e 2019 (37) aumentou 54,17\% e por último, a amarela, entre 2014 (2) e 2019 (1), reduziu 50,00\%. Fazendo a análise do sexo feminino, na faixa etária de 60 a 69 anos, entre 2014 (164) e 2019 (264) houve aumento de $60,97 \%$. Verificando as etnias dessa faixa etária, a branca apresenta entre 2014 (93) e 2019 (150) aumento de 61,29\%; a preta entre 2014 (12) e 2019 (20) aumento de 66,67\%; já a parda entre 2014 (23) e 2019 (59) teme aumento de 156,52\%; e por fim, a amarela entre 2014 (1) e 2019 (2) aumentou 100\%. Vendo a faixa etária de 70 a 79 anos, o sexo masculino entre 2014 (153) e 2019 (179) teve aumento de 16,99\%; o sexo feminino entre 2014 (142) e 2019 (162) 
aumentou 14,08\%. Estudando as etnias, a branca, apresenta entre 2014 (72) e 2019 (103) aumento de 43,05\%; analisando a preta, em 2014 (7) - 2019 (14) aumentou 100\%; e a parda apresenta entre 2014 (31) - 2019 (28) redução de 9,68\%; e por fim da análise, a amarela, que apresenta aumento entre 2014 (1) e 2019 (2) de 100\%. A partir do estudo realizado, conclui-se que a etnia branca apresenta maior incidência de óbitos por hemorragia intracraniana dentre pessoas do sexo masculino, sendo que são idosos com idade entre 60 a 69 anos. Já no caso de homens entre 70 a 79 anos, comparando os anos 2014 e 2019, houve prevalência por aumento de $17 \%$ de óbitos pela doença.

Palavras-chave: Hemorragia intracraniana. Idosos. Incidencia. Meninges. Óbitos. 